\title{
Prevention of Teachers' Professional Burnout as a Way to Improve the Quality of Higher Education
}

\author{
Yuliia Skoryk $^{*}$ \\ Chair of Higher School Pedagogics and Education Management, Cherkasy B.Khmelnytsky National University, Cherkasy, Ukraine \\ *Corresponding author: alera_julija@mail.ru
}

Received September 27, 2013; Revised October 12, 2013; Accepted November 24, 2013

\begin{abstract}
The article considers the problem of teachers' professional burnout. Changing perceptions as to the phenomenon of professional burnout are generalized according to the historical stage of its study. The main theoretical approaches to the definition of the notion and psycho-physiological burnout structure are found. The factor analysis of teachers' professional burnout and stressor classification of professional character are presented. The stages of teachers' professional burnout and the main manifestation of psycho-physiological burnout phenomenon are determined. The classification of professional burnout symptoms is found. The influence of higher school teachers' psycho-physiological burnout formation on the level of pedagogical activity efficiency and education system functioning in general is analyzed. The level of application topicality and main approaches to the prevention measures of professional burnout are considered. Individual technology of psycho-physiological prevention is described. The programs of group form of professional burnout prevention are presented. The list of personality qualities of a specialist is proposed; their formation and development help to reduce the tendency to professional burnout. The methods of acquiring skills for stress management providing control for personal social and physical "I", the changes of consciousness content, reproduction processes, suggestion and rational thinking are described. The universal methods of resistance to stress factors of professional character are proposed.
\end{abstract}

Keywords: professional burnout, teacher, education system, professional burnout prevention

Cite This Article: Yuliia Skoryk, "Prevention of Teachers' Professional Burnout as a Way to Improve the Quality of Higher Education.” American Journal of Educational Research 1, no. 11 (2013): 496-504. doi: 10.12691/education-1-11-7.

\section{Introduction}

Social significance of a teacher's profession, the intensive development and improvement of the system of higher education causes permanent growth of requirements to the teacher' personality. Numerous studies confirm that the teaching activity is one of the most responsible. Emotional stress, frequent social contacts and a high level of responsibility for the professional activity of a teacher cause inclination to mental and physical burnout. Professional burnout has significant impact on the level of skill and professionalism of a teacher. Since future and working teachers aren't aware of the possible consequences of emotional exhaustion, ways to prevent it, they don't concern with the formation of qualities that increase the level of stress fortitude. Therefore, the professional challenges seem insurmountable, and the quality of higher education does not reach the desirable level. To define the possible ways and directions of preventing the professional burnout means to find a significant mechanism to improve the efficiency of educational activities in general.

\section{The Phenomenon of Professional Burnout}

The phenomenon of burnout was first noted by scientists in the 70th years of the twentieth century. Professionals working in the system of professional interaction "man-man", and involved in the field of communication activities (teachers, doctors, psychologists, social workers), complained about the emotional exhaustion. A more detailed analysis of current professional activity of the workers made it possible to notice a process of gradual loss of interest in their profession, some disappointment and formalism in regard to their duties, higher level of conflict in a collective. Further researchers' observations proved negative changes of physical condition, that is ill health and symptoms of psychosomatic disorder in the groups of emotionally exhausted specialists. The reason for those changes, as it was found out later, had been the influence of lasting stress of a professional character. To indicate the mentally healthy professionals who suffer from emotional distress, loss of interest in professional activity, accompanied by worsening of psychological climate in the team, an American psychiatrist Freudenberher H. J. introduced the concept of «burnout» in 1974. At that time, a social psychologist Maslach C. described the professional burnout as a phenomenon of emotional and physical exhaustion that arose from not only professional stress, but also intense interpersonal communication. According to Maslach C., the psychophysical exhaustion is the 
formation of negative attitude to work, reducing selfappraisal of one's competence and professionalism, and disorder in communicative sphere of a specialist [28]. The phenomenon of burnout is defined by Professor Storli F. J. as a state of exhaustion of the human spirit with fight against the circumstances, when professional activity is carried out mechanically, without proper emotional contribution [2]. An American researcher Cherniss C. describes the professional burnout as lack of correspondence between the occupational demand and the psychophysical resources of a specialist. This imbalance causes the loss of motivation to the profession in an employee, a sense of overstrain, stress, emotional distress, anxiety [25]. Scientists Edelwich J. and Brodsky A. consider professional burnout a process of progressive disappointment. In their view psychophysical burnout is the consequence of the loss of life goals through poor working conditions [26]. A Russian scientist Orel V. Y. offers to concider professional burnout as a state of emotional, mental and physical exhaustion that results from intense emotional interaction during professional social communication [10]. Among the higher education professionals, studying the phenomenon of burnout and dedicating their research to the problem, are Byelorussian researchers (Pashuk N. S., Skuharevska M. M. and others). It should be noted that there are some Ukrainian researchers: Bulatevich N. M., Zajchikova T. V., Karamushka L. M., Maksymenko S. D., studying the preconditions, symptoms, preventive measures of pofessional burnout among teachers. In her scientific research, Zajchikova T. V. explains the phenomenon of mental and physical burnout of teachers as a result of long-term stress of professional character, and she conventionally divides its root causes into three groups: individual psychological, social psychological, and socio-economic [5].

According to the definition of the World Health Organization, the burnout syndrome is a physical, motivational or emotional exhaustion, which is characterized by impaired productivity at work, and increased susceptibility to physical illnesses. The International Classification of Diseases (I.C.D.-10) places the burnout syndrome under the heading "Problems associated with complications to overcome life's difficulties, problems of managing one's life” (Z 73.0) [34]. Current views on the structure and dynamics of burnout do not give a clear generalization. However, a detailed analysis of the phenomenon of the psychophysical burnout proves its destructive nature and increases the urgency of creating the environment for training and working of professionals, that would ensure the harmonious development of an individual, ensure the process of professional development, and improve productivity on the whole.

\subsection{Psychophysical Burnout as a Destructive Phenomenon}

Numerous studies point to the relationship between the helping professions` specific type that includes intense, emotional communication with communicants and professionals` propensity to burnout. Social workers should possess a number of characteristics such as empathy, communication, humanism, tolerance. In the system of professions of "human - human" type much of professional activities are devoted to social communications. Compliance of a worker with the requirements of professional occupations requires significant physiological and psychological costs. However, with the time running psychophysical resources of a worker exhaust since professional overload provokes a state of physical, mental and emotional exhaustion $[4,7,16]$.

Professional burnout is often compared with regression of a specialist professional development. This is connected with the phenomenon destructive impact on the individual as a whole, since it reduces the effectiveness of professional activity. Psychological science denies the identity of the phenomenon of burnout with depression, stress or fatigue. The main difference between them is the relationship of mental and physical burnout with a professional activity. There are different subjective feelings of people who are in a particular state. Psychophysical burnout is an irreversible phenomenon and, compared with the state of fatigue or stress does not go away with rest [15]. Numerous studies confirm the high propensity of teachers to professional burnout .If to take into account the data given by Orel V. E. in his scientific work, the employees of educational institutions occupy top positions in the average performance level of burnout symptoms (Table 1) [10].

Table 1. Average Performance Characteristics of Burnout among Specialists of Different Professions (in \%)

\begin{tabular}{|c|c|c|c|}
\hline \multirow{2}{*}{ Professional group } & \multicolumn{3}{|c|}{ Components of burnout } \\
\cline { 2 - 4 } & Emotional exhaustion & Depersonalisation & Professional performance \\
\hline Schoolteachers & 21.25 & 11.0 & 5.57 \\
\hline Professors & 18.57 & 33.54 & 3.46 \\
\hline Social workers & 21.35 & 3.12 & 32.75 \\
\hline Health professionals (doctors, nurses) & 22.19 & 36.53 \\
\hline Staff workers of counseling services & 16.89 & 30.87 \\
\hline Other professions (lawyers, police officers, surveillance \\
services, librarians, etc.).
\end{tabular}

The most troublesome period of teacher`s burnout is the initial phase as a beginner is usually not aware of the phenomenon 'manifestations and explains them as daily exhaustion. In such cases, the presence of mental and physical burnout is more noticeable when observed by an expert, as during supervision. The phenomenon of burnout has certain characteristics that help in recognizing deformation processes of the individual specialist:
- job dissatisfaction, disappointment in the profession;

- reducing the level of responsibility;

- indifference as regards to professional duties;

- feelings of guilt;

- non-compliance with professional requirements and so on.

Whereas to prevent the burnout is easier than to remove it, you should be attentive to the factors that contribute to 
the development of mental and physical burnout. The level of teacher 's ability to resist occupational stress influences not only on the psychophysical state of a specialist but on the quality of higher education in general.

\subsubsection{Background of the Professional Burnout}

For a long time, the main cause of the professional burnout was considered a specialist's work under stress. Now the burnout factors are conventionally divided into emotional, physical and social. A more common classification distinguishes two groups of factors of the psychophysical burnout: internal (relating to personal properties of the specialist) and external (stressful factors of some profession). These factors influenceon the specialist at one and the same time, exhausting the human by the non-conformity between the demands of the profession, the needs of the social environment and availability of all the resourcesfor the professional to meet those needs. The desire of the employee to meet the needs of the society leads to fatigue and exhaustion of his organism, which in turn causes the formation of the professional burnout.British psychologist Fontana D. refers to common stressors of the profession the following [27]:

- irrational organization of collective activity (irresponsibility, lack of system at work);

- insufficient number ofstaff, exhausting workregime;

- violation of the operating mode, overtime work, which causes exhaustion, fatigue accumulation, psychological overload;

- lack of career prospects, low wages;

- formalism, an excessiveamount ofpaperwork;

- unpredictability, instability of the organization's development.

Among the specific professional stressors Fontana D. distinguishes:

- the level of employee claims;

- lackof regulated duties;

- difficulties in the field of communication with colleagues;

- indifference of the head of the organization to the ideas and needs of the employee;

- stressors of domestic nature (related tofamily).

Using the experience of foreign scientists, as well as on the basis of their own research, Ukrainian scientists Zaichikova T. V., Karamushka L. M. and Maksymenko S. D. formed amodel ofoccupational stressors of the professionals in the sphere of education. The authors combined factors that contribute to the formationof professional burnout, into three blocks:

1. Socio-psychological and socio-economic factors:

- the level of development of social relationships and social services of psychological support;

- socio-economic level of the country;

- the level of the education system.

2. Conditions of work:

- socio-psychological climate in the working group;

- the style of management in the organization;

- the structure of the organization;

-specific course of the organizational processes.

3. Summary of work:

- volume of work;

- the level of professional aspirations;
- correspondence of one's appointment to his/her professional level;

- peculiarities of social interaction between employees and managers;

- specificity of communications between colleagues;

- peculiarities of the interaction with pupils and parents;

- the intensity of the process of teacher's professional development [18].

The intensity of the impact of stress depends on the individual characteristics of the specialist, his/her experience, the relation to the situation in general. The specialist's attitudes to failure, his/her uncertainty and the diminished self-esteem increase the negative effects of stress. Performing educational activities a specialist can suffer from the following types of stress [22]:

- emotional - are formed during the conflicts between teachers and students; characterized by feelings of guilt, resentment, etc.;

- communication - can be caused by inconsistencies in communication styles, characterized by difficulties in communicative sphere of the specialist;

- information - caused by time constraints or excessive amounts ofinformation, leading to the failure of professional duties and tasks.

Russian psychologist Markova A. K. emphasizes the decisive role of the following three factors in the development of the professional burnout: role, personal and organizational [8].The studies confirm the link between the role uncertainty and the developing of the professional burnout. A clear division of responsibilities reduces the susceptibility to mental and physical exhaustion even under the conditions of excessive work. Taking into account the reforms in the education system in Ukraine, the value of role-factor increases. It can be assumed that the modern teacher needs to rethink its role in the relationship with colleagues and pupils and in the educational system in general. The awareness of the importance of the profession of the teacher and the personal responsibility of every teacher in shaping future generations would help to improve the quality of education.

Exploring the role of personal factors in the process of burnout requires taking into account the specialist's age, gender, work experience, marital status and social position [33]. Russian researcher Orel V. E. emphasizes the following specialist's personal characteristics that may cause the development of burnout: empathy, anxiety, intravertness, humanism. However, in contrast to these qualities, commitment, optimism, high self-esteem, resilience to conflict, prevent the development of mental and physical exhaustion [11]. Pines A. in his writings emphasizes the importance of studying the reasons of employment, levels of autonomy and control of the management [31]. Another equally important factor in the study of susceptibility to mental and physical burnout is sex. Ukrainian scientists Zaichikova T. and Karamushka L. argue that men following gender stereotypes are more prone to burnout.

According to Kondo $\mathrm{K}$. the organizing factor is the main in the development of the professional burnout. To the elements of the organizational factorthe scientist also adds unclear division of responsibilities, changes in the mode of work, the discrepancy of skill level of the employee to his/her post, the authoritarian style of 
leadership [30]. The formation of professional burnout syndrome cannot be explained by only individual factors, since this phenomenon is the result of the interaction between the individual characteristics of the specialist, his professional activities and the type of the communicative sphere. Up to time investigation of the tendency of teachers' professional burnout will help not only to develop measures of preventing them from this phenomenon of mental and physical burnout and improve their working conditions, but also to increase the performance indicators of their activity.

\subsubsection{Phases of Professional Burnout Development}

Now, there are several models of professional burnout, which interpret the structure of mentioned phenomenon differently. The authors supporting one-factor model of professional burnout Pines A. and Aronson E. consider it to be the state of emotional, physical and cognitive exhaustion, which is stipulated by the influence of emotionally difficult situations of professional character [32]. Two-factor model of professional burnout is suggested by Direndonk D., Sixma H. and Schaufeli V. The scholars explain the mentioned phenomenon as a structure, consisted of two components: emotional exhausting and depersonalization. Maslach C. and Jackson S. consider the phenomenon of professional burnout to be a three-factor structure, the components of which include emotional exhausting, reduction of professional achievements and depersonalization [29]. Emotional exhaustion is developed in the senses of emotional overstrain, devastation, possible emotional breakdown. The reduction of professional achievement is characterized by the emergence of professional incompetence senses, indifference to work, the emergence of dissatisfaction as to the results of their own activities and feelings of guilt because of professional failure. Depersonalization as a component of professional burnout involves the formation of specialist's indifferent, negative attitude to professional activities and objects of communication. Social contacts obtain formal and depersonalized nature. Accumulated hidden anger can sometimes be manifested in sudden conflicts and irritation.

Procedural models of professional burnout consider the phenomenon of professional burnout as a dynamic phenomenon having certain stages. Here the development of burnout lies in increasing the level of emotional exhaustion. British scientist Burish M. suggests detailed explanation of professional burnout process (Table 2) [14].

Table 2. Phases of Professional Burnout Development

\begin{tabular}{|c|c|}
\hline Phase & Display \\
\hline $\begin{array}{c}\text { Warning } \\
\text { Phase }\end{array}$ & $\begin{array}{c}\text { excessive participation in professional } \\
\text { activities, excessive activity; } \\
\text { exhaustion, insomnia, fatigue. }\end{array}$ \\
$\begin{array}{c}\text { to colleagues; } \\
\text { participation level } \\
\text { to professional activity; } \\
\text { to social environment; } \\
\text { concentration to their own needs. }\end{array}$ \\
\hline $\begin{array}{c}\text { Emotional reactions } \\
\text { Phase of destructive } \\
\text { behaviour }\end{array}$ & $\begin{array}{c}\text { in emotional and social spheres; } \\
\text { in motivational sphere; } \\
\text { in cognitive sphere. }\end{array}$ \\
\hline $\begin{array}{c}\text { Psychosomatic } \\
\text { reactions }\end{array}$ & $\begin{array}{c}\text { Headache, insomnia, disruption of the } \\
\text { gastrointestinal tract, the appearance of } \\
\text { psychotropic substance dependence. }\end{array}$ \\
\hline Disillusion & $\begin{array}{c}\text { Feelings of despair, helplessness, } \\
\text { formation of negative life position. }\end{array}$ \\
\hline
\end{tabular}

The dynamic model of professional burnout offered by Perlman B. and Hartman E describes professional burnout as a reaction to organizational stresses. The scientists believe the level psychophysical exhaustion to be due to the increasing symptoms evidence of psychophysical burnout [19].

Taking into consideration the existing models of professional burnout the three stages of teacher's personality burnout were outlined [21]:

- the first stage is characterized by failing professional functions performance. Specialist has neuro-mental stress, concentrates on numerous controlling of performed work activities.

- somatic symptoms of professional burnout (violation of daily time-table, exhausting, weakening of immunity, headache), lowering the level of work motivation and communication, increasing levels of irritability appear on the second stage.

- the third stage is the psychophysical burnout. This phase characterized by emotional indifference, physical exhaustion, lack of interest not only to professional activity but also to everyday life.

To determine the presence of professional burnout and ascertainment the phase of psychophysical phenomenon of burnout and its symptoms should be considered.

\subsubsection{Symptoms of Mental and Physical Exhaustion}

In 1981, social psychologist Maslach C. in their research identified the main characteristics and features of burnout. These scientists brought lower professional skills, emotional exhaustion, feelings of intellectual overstrain, lower self-esteem and appearance of negativity in relation to the social environment. In 1983, Maher E. supplement for mental and physical symptoms of burnout includes: the formation of negative "self-concept" constant feeling of fatigue, insomnia, aggression and increasing conflicts, formation of psychosomatic disorders. Today the symptoms of professional burnout have been studied quite extensively, however, their precise number has not been set. The most widely used classification was proposed by Schaufeli V. and Eisemann D. The scientists distinguish 132 symptoms of burnout that are conventionally grouped into five groups: affective, physical, behavioral, cognitive and motivational.

Affective symptoms are a manifestation of mental and physical burnout in the field of emotional and sensual personality, causing development of depression, reducing emotional and physical inventories of an employee. A person suffering from affective symptoms of burnout, experiencing anxiety, irritability, and fear. Communication sector is characterized by high levels of conflict and the professional sphere annoys specialist due to the prevailing feeling of discomfort in the workplace.

Physical symptoms of professional burnout consists of three categories. The first category includes variety of psychosomatic disorders (disturbance of the cardiovascular system, gastrointestinal tract). The second category includes complaints of physical weakness: dizziness, headache, pain in joints, muscles, and insomnia. The third category consists of individual physiological responses: increased cholesterol levels, increased blood pressure and others.

Behavioural symptoms of burnout are associated with higher levels of arousal in the individual psychological 
level. Hyperactivity, restlessness, inability to concentrate on a particular subject for a long time, straightforwardness, impulsiveness, indecisiveness - individual personality characteristics that may cause the development of burnout. Tensions provoke the use of stimulants (alcohol, coffee, tobacco, medicines).

At the interpersonal level of burnout the symptoms are associated with the two main forms of behaviour. One of the possible behavioural strategies is to avoid social contact to isolate socially. Another form of behavior involves a specialist's aggression and conflict in relations with not only colleagues but also his family. Professional activity is deprived of initiative, creativity and interest in professional duties.

Cognitive symptoms of burnout may occur on individual psychological, interpersonal, and organizational level. The symptoms of mental and physical burnout at the individual psychological level are characterized by the violation of mental functions and processes. There are possible violations of attention, memory, thinking processes and difficulties in decision-making. At the interpersonal level cognitive symptoms of burnout are shown in relation to inhuman objects communication. Organizational level of burnout symptoms is characterized by the formation of negative attitudes towards leadership and colleagues, excessive criticality to the social environment, which can cause excessive irritability and aggression in relation to peers.

Motivational symptoms of burnout on a personal level professional are a manifestation of the internal conflict between the idealized notions of professional activity and the actual working conditions. It is possible to reduce the significance of the work. Symptoms of professional burnout at the interpersonal level are commercialism, indifferent attitude to business communication and to their needs. At the level of motivation the manifestations of burnout are related to unwillingness to work, to perform professional duties and tasks, to be active and take responsibility [9].

Russian psychologist Samoukina N. V. conditionally divides the symptoms of burnout into three groups and offers the following classification :

1. Social and psychological symptoms:

- unjustified feelings of negative emotions;

- high level of irritability;

- the emergence of nervous breakdowns;

- apathy, depression, passivity;

- anxiety;

- formation of negative attitudes about professional perspectives;

- feelings of fear and excessive liability.

2. Psychophysical symptoms:

- a sense of physical and emotional exhaustion ;

- the feeling of fatigue;

- decrease in activity, energy, reactivity, susceptibility;

- headache, weight fluctuations, insomnia;

- reduction of sensory sensitivity.

3. Behavioural symptoms:

- a dramatic change in routine work day;

- subjective feeling emergence of difficulties in the performance of duties;

- rejection of decision-making in the profession, which explains colleagues subjective, false arguments;
- indifference to the results of professional activity, reducing enthusiasm;

- avoidance of core tasks, excessive focus on performing basic professional activities;

- detachment from colleagues, the appearance of excessive complexity and criticality to the social environment;

- the emergence of bad habits [17].

\subsection{The Relationship between Burnout Phenomenon and the Level of Effectiveness of Educational Activities}

Responsibility for professional burnout of professionals often rely on the workers themselves. In fact, before a person takes a position he or she undergoes professional stress. Professional burnout is the result of a complex interaction of internal and external factors that are associated not only with the profession but with education, position in society, family relationships, individual characteristics of a person. Influence of mental and physical burnout on the personality changes his behavior, feeling, thinking, and professional activities. It affects the functioning of the higher educational establishment and educational system in general.

A teacher who is suffering from symptoms of burnout unable to maintain productivity of his or her activities at a proper level.

In addition, a person who has already undergone professional burnout can be a factor for burnout of colleagues and the institution as a whole. The formation of psycho-emotional symptoms of mental and physical burnout among teachers may lead to a peculiar professional burnout of the whole educational establishment.

Professional burnout of organization is more common in cases when the employees are not satisfied by the results of their own profession, pessimistic about the changes for the best in the development of organization.

Factors that contribute to the formation of professional burnout can be conflicts between tactical and strategic management, frequent organizational and staff changes, steep demands to workers, subjective evaluation of professional activities, inefficient system of team motivation, grant of authority to those who do not meet post.

Psychophysical state of teachers has a direct impact on the functioning of the educational establishment. Russian psychologist Asmakovets A. confirms that the psychological state of a teacher is closely related to the level of effectiveness of teaching students, the level of conflict in relationships with colleagues, parents, children. Teacher's negative psychological state determines the formation and consolidation of the negative traits of professionally important qualities of teacher's character, causes negative self-protection strategies, high tension identity level [1].

Today teaching process is personality-centered. It leads to the fact that teacher's individual traits actively interact with students' personal traits. It means that the efficiency and success of students' learning is directly dependent on the professionalism and personality of a teacher. Therefore, harmoniously developed personality of a teacher, the breadth of his outlook, the level of training methodology 
knowledge, and, what is the most important - the development of such character traits that are desirable to develop in students - are an important prerequisite for the success and effectiveness of teacher professional activity and therefore of higher education.

\subsubsection{Professional Burnout Prevention Directions}

Teacher's professional burnout prevention should have a complex character and be aimed at removing violations of the specialist's psychophysical state. Modern psychophysical burnout prevention is a complex of mesures which are conventionally divided into three directions of work.

1. The activity organization. A rational activity management plays an important role in lessening of the professional stressors' influence on the specialist's personality. Career growth opportunities provision, a distinct duties and job instructions division, elevating of the workers' level of motivation, forming a favourable psychological climate of the staff are the main prevention measures against professional exhaustion which can be applied by the administration [23].

A positive influence will be made by including trainings aimed at forming a rational time division skills and at the growth of self-evaluation level and relaxation techniques in the programs of pedagogues' qualification improvement. A rational organization of one's working place and his day schedule plays an important role in professional burnout prevention. Providing pedagogues with the necessary teaching, methodological and inquiry materials and technical means is useful. As for the working place, it should meet sanitary and hygienic requirements and the day schedule must include breaks sufficient for duration recreation.

2. The staff's socio-psychological climate improvement. The general task of this direction is the formation of staff as an integral group of people able to support one another in stress situations. An important factor of professional burnout prevention is the staff's favourable psychological climate provision. Difficulties in emotional relief can be solved with the help of participation in psychological trainings favouring the formation of tolerance and mutual understanding [3].

3. The work with individual peculiarities. Professional burnout prevention supposes psychological work with pedagogues consisting of three directions each of which corresponds to the professional burnout component noticed. The first direction is to reduce the level of negative personal and professional factors. It is important to develop the specialist's skills to rationally solve situations of conflict, to reach the aim set, to make constructive decisions and to overestimate the activity motives which hinder personal and professional development.

Usually this direction of the professional exhaustion prevention applies trainings and practical classes that help to increase the level of self-assurance, to improve the personal development and self-improvement process. The second direction of the work with the specialist's individual peculiarities is aimed at the pedagogue's activity and creativity development. Creativity should be understood as labiality, quickness and originality of one's way of thinking as well as a feeling for humour, a rich imagination. That is to consider creativity as a person's development factor which is favourable for avoiding stereotypes. The third direction secures the specialists' emotional relief, the increase of the stress-resistance level, forming the skills of self-regulation and one's psychophysical state's control [6].

Professional burnout prevention and overcoming programs have two forms: individual (including psychological methodologies and being realized on the specialist's personality level) and group ones (suggesting work with the staff). To the individual form programs belong self-trainings, time planning and division techniques, exercises for fighting negative thoughts, relaxation classes and exercises favourable for the worker's emotional relief. At the staff level important for the professional exhaustion prevention is mutual understanding, social support and friendly interrelations provision. The following programs are referred to the group form of the psychophysical exhaustion prevention.

1. Support is a unique informal procedure which can vary in its ways but it has the only aim - the staff's emotional relief at the end of their working day.

2. Supervision is a way of keeping to the work standards with the help of planned actions of the supervisor. There are three forms of supervision: formal, informal and self-supervision. Formal supervision is done by the governing person as a supervisor and it aims at the supervision of the worker's skills formed and his potential's activation. Informal supervision differs in the person who's evaluating the staff's work. To increase the evaluation's objectivity level an independent person is employed for informal supervision. Self-supervision is a form of self-analysis and self-evaluation of one's own professional activity, control of work drawbacks and timely removing mistakes.

3. Help within a group is a collective professional communication which helps specialists to keep a high proficiency level based on discussing the experience and theoretical knowledge obtained.

4. Relaxation is a procedure of leaving the state of being tense, removing emotional constraint and physical exhaustion. Art-therapy, meditation, physical exercises, massage and other methods are referred to relaxation ones [24].

Ukrainian scientists Zajchikova T. V. and Karamushka L. M. offer an individual technology for psychophysical burnout prevention. It consists of two phases and a number of definite devices.

The first phase is the analysis of a professional situation, its cognitive evaluation which lies in finding stressors of a professional character, in the analysis of one's own tolerance level, stress reactivity and in the reduction of stress factors influence. The following devices are applied in the first phase:

1. Stress recognition - the identification of organism signals which witness a stress state formation.

2. Cognitive evaluation of the situation - finding out of the active stress factors of a professional character and their removing.

3. Keeping record of stress events of the working day.

4. Working out a rewarding system for keeping the professional exhaustion prevention rules.

5. The establishment of a system of motives the specialist is being governed by while doing his professional duties. 
6. Learning skills of a rational working day regime management.

7. Acquiring a sure style of behaviour and the increase of a specialist's self-evaluation level.

8. Belonging to a social support group.

9. Keeping a balanced diet.

The second phase is the one of perceiving a situation as characterized by stress. Zajchikova T. M. and Karamushka L. M. recommend the application of the following devices in order to remove the professional burnout symptoms:

1. Optional perception.

2. Positive and optimistic attitude to the professional activity.

3. The application of humour as an organism's defensive reaction to the conditions of stress.

4. Analysis and control on one's own life events.

5. The application of physical exercise, autogenic training and meditation techniques as the means of fighting psychophysical exhaustion symptoms [18].

\subsubsection{Teacher's Personality Characteristics that Resist the Development of Professional Burnout}

Higher school plays an important role in the system of education. This branch of professional training performs general cultural functions, develops morality and world outlook of would-be specialists, it ensures the conditions for multifaceted and harmonious development of trainees' personalities, the teacher serves as a model for further generations. So we can come to the conclusion that the teacher's individual virtues are of great importance in the educational process. Some of the Ukrainian scholars (Sysoyeva S, Kruten'ky V. O., Shcherbakov O. I. etc.) study the essential characteristics of teacher's professiogram. Sysoyeva S outlines the principal features of pedagogical mastery as follows [20]:

- self-management abilities and skills;

- high standard morals;

- communicative abilities and skills;

- high level of social consciousness;

- intellectual and logical talents;

- special types of vocational motivation (aspiration for improvement, self-realization, higher results of professional activity);

- special individual features of personality (commitment, interest, perseverance, independence, enthusiasm etc.).

However, there are destructive phenomena, including professional burnout, that cause the modification of specialist's personality characteristics, contribute to the consolidation of negative qualities.

Hence, it seems reasonable, in the process of teacher training, to gain both the generally accepted features and the characteristics that prevent the development of professional burnout as well as mould individual ability to resist stress. To such characteristics scholars refer the following [18]:

- self-efficiency, a specialist's confidence in his own level of professionalism, a well-organized and shaped aim to achieve success;

- tolerance to difficulties, to unpredictable situations;

- self-respect, adequate level of self-estimation;

- fortitude, ability to manage affairs of professional character;

- development of individual strategies to overcome stress etc.

\subsubsection{The Preventive Methods from Psychophysical Burnout}

As to the practical recommendations of preventing from the burnout of the teacher's individuality, the methods aimed at the acquisition and improvement of skills of managing stress are conventionally divided into six groups [13]:

1. The methods of management of the physical "I". They are aimed at the self-mastery skills and involve the use of relaxation techniques, breathing exercises (breathing exercises, breath holding), and setting clear goals of physical activity.

2. The methods of the awareness of your own social "I". They need to build short-term and long-term professional goals, which provide long-term incentives to the profession, increase the level of self-education and professional satisfaction from the performed activities.

3. The methods of the changing the contents of consciousness. These methods are aimed at developing the ability to be distracted from emotionally significant events, experiences and focus on the objects of the environment.

4. The methods of the reproduction of positive images. The nature of the embodiment of the methods of this group is the most difficult but most effective. The mechanism of these methods lies in the ability of a specialist to switch his attention from a stressful situation to the apparent positive situation. This transfer of images is realized by means of recalling some pleasant scene images and playing physical, auditory, visual, tactile sensations that were inherent to these positive images.

5. The methods of the eliminating of irrational beliefs. The activity of these methods aims to replace the identified irrational beliefs by the rational ones.

6. The methods of the positive suggestion. They are used by means of permanently realized positive thinking to achieve long-term constructive mood and increase satisfaction by professional activity.

The following techniques can help to withstand a stress and the influence of stressful factors [12]:

1. The method of "Visualization". You should try to monitor the situation from the third person. It is better to relax, follow the breath and focus on internal feelings. The advantage of this method is in an attempt to evaluate events as objectively as possible while remaining in a state of emotional balance.

2. The method of "Magic eye". A focusing look on the eyes of the man exercising psychological pressure on a subconscious level gives an opponent a sense of indestructibility, confidence, and dominance. Strongwilled and calm look confuses your interlocutor and you can show your own advantage.

3. The method of "Suspension". The method is based on the separating of the professional from the given situation by means of imaginably built wall, thickness of air, water or tissue. This technique avoids the emotional impact of the situation on the psycho-physical state of a person.

4. The method of "The change of tactics". The technique lies in the unpredictable change of behavior in a stressful situation. The strategy of the specialist's behavior must first change to a completely opposite one and then gradually turn into a reaction that would be most optimal is the given situation. Such dramatic changes in behavior 
are forcing participants to adapt to the behavior of the person who uses the technique.

5. The method of "The manifestation of sympathy". If the psychophysical state of an employee is influenced by the actions of the other person (a colleague, a subordinate, administration), he should try to express a non-verbal sympathy in the attitude to the opponent. The focus on feelings will distract from the interlocutor's aggression and will reduce the level of his influence.

6. The method of "The level of happiness". The method consists in comparing the significance of situations. The memories of everything that makes us happy, be thankful will help to have a new look at the problem. After recalling of some happy moments the difficulties do not seem so complicated.

7. The method of "The center of rest". We visualize a small part of ourselves that is perfectly happy, and then follow its imaginary exaggeration.

8. The method of "The secret little house". The technique is based on an imaginary small house in which a mentally exhausted specialist can come to relax, recharge psychophysical resources. The method will help to move away from the influence of stress and maintain emotional balance.

The purpose of the above techniques and exercises is the management of burnout, the recovery of the specialist's internal resources. Among a great number of methods of preventing from psychophysical burnout a specialist should choose the most effective and suitable for him. The awareness of the specifics of burnout and the ways of preventing it can significantly mitigate the influence of organizational and personal factors which cause the psychophysical exhaustion.

\section{Conclusion and Recommendation}

If we summarize all the above mentioned facts, we can conclude that professional burnout is the state of emotional, mental and psychophysical exhaustion determined by the conditions of professional activity, excessive working load and emotional interpersonal communication. The phenomenon of psychophysical burnout has destructive character and influences negatively not only the activity of a professional teacher, but his personality as well. It is impossible to foresee the development of the phenomenon, because the specific character of the professional burnout depends on the person's individual peculiar features, his working conditions and such a concurrence of circumstances, which can cause psychophysical burnout. As a structure the phenomenon of professional burnout consists of three components: emotional exhaustion, depersonalization and reduction of professional achievements. Each component of the phenomenon can become apparent through complex of symptoms: emotional, behavioural, somatical, cognitive and motivational.

Preservation of teachers' psychophysical health is acquiring its topicality and urgency because of the significance of the results of teachers' professional activity in the cource of raising of the quality level of higher education. The phenomenon of professional burnout, that is to say regulation of teachers' emotional, physical and intellectual condition is one of the most important psychological and pedagogical problems, which calls for immediate solution. The syndrome of the psychophysical burnout, which can be a characteristic feature of an individual teacher and of an educational establishment as a whole, is an important obstacle on the way of improvement and innovational changes in the system of high school.

Diathesis level to professional burnout can be lower among teachers whose attitude to the teachers' training process is creative, who long for personal and professional development, improvement, who are satisfied with the quality of their activity and have some perspectives and intrests beyond the limits of their work. The teachers who have cheerful, life-asserting, purposeful character, lead an active way of life are ready to meet difficulties, they possess every possible means of self-regulation and refreshing of social and psychological resources and they seldom suffer from the symptoms of professional burnout.

Numerous investigations of European and American scientists are connected with the working out of the prevention methods of the professional burnout phenomenon. We see the perspective of the further investigations in the setting up special courses or in educational and methodical programmes, which could inform present and future teachers of specific character of possible concurrence of circumstances and of the ways of elimination of the professional burnout symptoms.

\section{References}

[1] Asmakovets, E.S., Psychological factors and conditions for the development of emotional flexibility teacher: abstract of thesis ... candidate of psycho. science, Moscow, 123.

[2] Vodopiyanova, N.E., Burnout syndrome: diagnosis and prevention, Publishing House of the "Piter", St. Petersburg, 2005, 336.

[3] Gnezdilov, A.V., Psychology and Psychotherapy losses, Publishing House of the "Rech", St. Petersburg, 2004, 162.

[4] Grishin, N.V., Helping relationships: professional and existential problems // Psychological problems of self-identity, Publisher of the St. Petersburg University, St. Petersburg, 1997, 143-156.

[5] Zaychikova T.V. Socio-psychological determinants of the syndrome of "burnout" in the classroom: abstract of thesis ... candidate of psycho. sciences, Kyiv, 20.

[6] Zborovskaya, I.V., "Self-regulation of mental stability teacher", Applied Psychology, 6, 55-65, 2001.

[7] Eldyshova, O.A., Professional burnout in the helping professions. The role of the emergency services counseling over the phone to solve the problem of orphanhood in Russia: I International Conference children's helplines, Moscow, 38-41.

[8] Markov, A.K., Work Psychology teacher, Publishing House of the "Education", Moscow, 1993, 192.

[9] Orel, V.E., Mental burnout syndrome personality, Institute of Psychology, Russian Academy of Sciences, Moscow, 2005, 330.

[10] Orel, V.E., "The phenomenon of "burnout" in Western psychology: An empirical study”, Psychological Journal, 22 (1), 90-101, 2001.

[11] Orel, V.E., Structural and functional organization and genesis of mental burnout: abstract of thesis. ... doctor of psyho. science, Yaroslavl, 51.

[12] Osuhova, N.G., Kozhevnikov, V.V., Return to Life: Teaching materials for leading workshops and seminars on the prevention of burnout, Publishing House of the "Amigo-press", Moscow, 2006, 96-112.

[13] Pashuk, N.S., Prevention of burnout: the ways and forms of address, Publishing House of the MIU, Minsk, 2008, 412-413.

[14] Petrovic, V.S., "Ways of preventing and overcoming burnout specialist of social and educational spheres", Scientific Bulletin Volyn National University, 17, 130-135, 2011.

[15] Psychological Encyclopedia, authored by A. Stepanov, Publishing house "Akademvydav", Kyiv, 2006, 424. 
[16] Ronginskaya, T.I., "Burnout syndrome in social professions," Psychological Journal, 23 (3), 19-24, 2002.

[17] Samoukina, NV, Psychological Training for Teachers: Tips psychologist, Publishing House of the "Psychotherapy", Moscow, 2006, 187.

[18] Syndrome of "burnout" and a professional career employees of educational institutions: gender / Under scientific. ed. S.D. Maksimenko, L. Karamushko, T.V. Bunnies, Publishing House of the "Millennium", Kiev, 2006, 368.

[19] Reference Dictionary [Accessed date of access]. Available: http://psyfactor.org/personal

[20] Sysoeva, S., Preparing teachers for forming a creative student, Publishing House of the "Polihrafknyha", Kyiv, 1996, 406.

[21] Sushentsova, L.V., Professional burnout teacher: the nature, diagnosis, prevention, Publishing House of the "Mar. State. Univ", Yoshkar-Ola, 2006, 190-198.

[22] Turkot, T.I., Pedagogy of Higher Education, Publishing House "Condor", Kyiv, 2011, 628

[23] Formalyuk, T., "Syndrome" burnout "as an indicator of professional teachers maladjustment", Questions of psychology, 6, 57-64, 1994.

[24] Chubuc R.V., "Overcoming burnout in future social workers", Scientific works: Research and methodological journal, 184 (172), 102-105, 2012.
[25] Cherniss, C., «Long-term consequences of burnout: An exploratory study», J. of Organizational Behavior, 13 (1), 1-11, 1992.

[26] Edelwich, J., Brodsky, A., Burn-out: Stages of Disillusionment in the Helping Profession, Human Scinces Press, New York, 1980.

[27] Fontana, D., Managing Stress, The British Psychology Society, 1989.

[28] Maslach, C., Professional burnout: Recent developments in the theory and research, Taylor \& Francis, Washington D.C, 1993, 19-32.

[29] Maslach, C., «Burned-out», Human Behavior, 5 (9), 16-22, 1976.

[30] Kondo, K., «Burnout syndrome», Asian Medical Journal, 34 (II), 49-57, 1991.

[31] Pines, A.M., «A psychoanalytic-existential approach to burnout demonstrated in the cases of a nurse, a teacher, and a manager», Psychotherapy: Theory/Research/Practice/Training, 39 (1), 103113, 2002.

[32] Pines, A., Maslach, C., «Characteristics of staff burnout in mental health settings», Hosp. Community Psychiatry, 29, 233-237, 1978.

[33] Thornton, P., «The relation of coping, appraisal, and burnout in mental health workers», J. Psychol., 126 (3), 261-271, 1992.

[34] World Health Organization. The ICD-10 Classification of Mental and Behavioral Disorders: clinical descriptions and diagnostic guidelines, WHO, Geneva, 1992. 